\title{
Active Thermography with Microwave Excitation - Phantom Studies ${ }^{1}$
}

\author{
by A. Nowakowski, M. Kaczmarek, P. Debicki ${ }^{\star}$ \\ Department of Medical and Ecological Electronics, *Department of Microwave Engineering and Optical \\ Telecommunication; Technical University of Gdansk, Narutowicza 11/12, 80-952 Gdansk, Poland; \\ e-mail: antowak@pg.gda.pl; mariusz@biomed.eti.pg.gda.pl; pid@pg.gda.pl
}

\begin{abstract}
:
Different sources of irradiation - microwave and optical: infrared lamps, halogen lamps, semiconductor photodiodes and lasers - used for comparison of active thermography experiments are evaluated. The main task is to find if microwave excitation is, according to our expectation, reasonably better than optical one in terms of its use in breast cancer diagnostics. Gel phantom studies with use of different excitation sources and thermographic measurements of forced temperature changes are related. Final conclusion - in medical experiments and diagnostics optical sources seem to be more handy and safe in use.
\end{abstract}

\section{Introduction}

Use of thermography in screening of breast cancer was widely introduced in late sixties and then given up due to not reliable enough results of diagnostics. As thermography is a fully non-invasive and safe technology and recently it's very fast development in terms of technical parameters is observed it is a great pity that this technique is no more widely accepted by medical doctors. The aim of this work is to answer the question - are there any chances to improve breast cancer detection by active thermography especially using microwave excitation? Other medical applications of the method related to skin diseases, burns and transplants are also studied.

Basic problems are related to evaluation of optimal parameters of heating pulses and safety of a measurement procedure. IR Thermography allows measurements only of surface temperature changes therefore other important question is what is the dependence of a surface temperature on time and on the internal structure of a tested object as well as on the initial conditions of the heating or cooling processes. Especially important is the knowledge of the volumetric distribution of the microwave power resulting in non-uniform spatial generation of heat and temperature distribution while heating and cooling, enabling detection of internal structure of a tested object, as e.g. breast cancer.

To answer those questions the experimental studies as well as modelling of thermal processes are performed.

\section{Theory}

Use of a microwave source is related to the absorption of electromagnetic wave resulting in a rise of temperature of internal structure of an irradiated object - affected tissue in the case of medical applications. SAR - specific absorption rate, gives a value of the microwave power absorbed in a tissue. SAR is defined as a power dissipated in the mass unit:

$$
S A R=\frac{P_{q}}{\rho_{t}}=\frac{\frac{1}{2} \sigma|E|^{2}}{\rho_{t}}, \quad S A R_{n}=\frac{S A R}{S A R_{\max }},
$$

where: $P_{q}$ - volumetric dissipated power density, $\sigma$ - electric conductivity of a tested material, $E$ - amplitude of electromagnetic field, $\rho_{t}$ - mass density, $\mathrm{SAR}_{\mathrm{n}}-$ normalised SAR to its maximum value.

\footnotetext{
${ }^{1}$ This work was financed by the KBN grant 8 T11E 03015
} 
The SAR evaluation based on (1) is usually difficult. But indirect method is possible using a thermal camera which enables to take temperature distribution on the tissue surface after it short irradiation by microwave. In that case the bio-heat transfer equation, originally introduced by Pennes [1] takes the form:

$$
c_{t} \rho_{t} \frac{d T(x, y, z)}{d t}=Q_{z}=\frac{1}{2} \sigma|E(x, y, z)|^{2},
$$

where: $c_{t}$ - specific heat, $\rho_{t}$ - mass density, $Q_{z}$ - volumetric dissipated power density of heating source (e-m field).

It is visible that thermal conductivity might be omitted during a short time after irradiation and $\mathrm{SAR}_{\mathrm{n}}$ may be calculated basing on temperature measurements. It is proportional to the temperature increment:

$$
S A R_{n}=\frac{T(x, y, z)-T_{s}(x, y, z)}{T_{\max }-T_{\min }} * 100 \%,
$$

where: $T$ - temperature after heating, $T_{s}$ - steady state temperature before heating, $T_{\max }-$ highest temperature in the object after heating, $T_{\min }$ - lowest temperature in the object before heating. For uniform tissue the normalised SAR distribution is proportional to the square of the electric field distribution in the object.

One of the simplest thermal models (two layer) may be described by the expression:

$$
\Phi(t)=A 1^{*} \exp \left(-A 2^{\star} t\right)+A 3^{*} \exp \left(-A 4^{\star} t\right)
$$

where: $\mathrm{t}$ - time, $\mathrm{A} 1 . . \mathrm{A} 4$ - thermal model parameters (A2, A4 - equivalent time constants; $\mathrm{A} 1$, A3 - equivalent excitation values). Calculation of the model parameters may be performed basing on time dependent temperature changes using dynamic thermography data. The reconstruction procedure using the fitting algorithm allows to estimate the model parameters. The resulting values are dependent on physical features of a tested object.

\section{Experiment set-up}

For simulation of biological tissues several phantoms of different mechanical, electrical and thermal properties are prepared basing on gel technology - $150 \mathrm{~g} / \mathrm{l}$ dry gelatine and using solutions with different concentration of $\mathrm{NaCl}$ and different geometric shapes - as it is shown on fig. 2. Thermal performances of the phantoms were measured using especially developed for the purpose of that research instrument [2].

The results of performed measurements show that thermal properties of the phantoms are close to the properties of biological tissues (see tab. 2). Therefore the results discussed in the following paragraph may be regarded as representative also for in vivo (for tissue with small blood flow ratio) and in vitro measurements.

The experimental set-up is composed of:

- the Agema 900 IR thermographic camera and especially developed software for pulsed and lock-in experiments. It allows visualisation of temperature distribution and time dependent parameters;

- the microwave $2.45 \mathrm{GHz}$ applicator originally designed for hyperthermia experiments $[3,4]$. It was adopted for phantom studies of breast NDT. It is shown on fig.1; the most important is relatively big (12 cm in diameter) surface of the applicator suitable for mammographic experiments and allowing microwave power distribution on reasonable level. The practical solutions of other microwave applicators used in hyperthermia may vary in shape and design but typically a direct contact of such source with examined tissue is necessary. Therefore there are two phenomena existing in practice electromagnetic field is dissipated inside a tested object and instantly thermal interaction of the source and the tested object is evident. This interaction is affecting the thermal process. Additionally mechanical action to remove the source to allow thermographic measurements is necessary. 

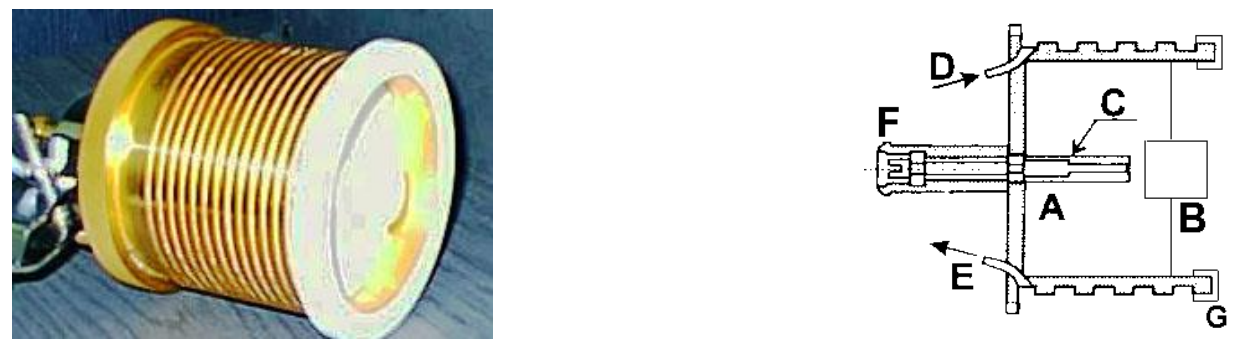

Figure 1. Cylindrical flange-waveguide microwave applicator - $\mathrm{TM}_{01}, A-$ a coaxial feeding and matching line, B - cylindrical waveguide with teflon rod, C - teflon sheath, G - teflon cover, D, E coolant inlet and outlet, F - an electrical connector

- a variety of optical excitation sources used for comparison experiments including:

a set of halogen lamps - up to $1000 \mathrm{~W}, \mathrm{IR}$ lamps of different power,

a set of semiconductor photodiode emitters $-878 \mathrm{~nm}, 1.5 \mathrm{~W}$,

several lasers:

- $\mathrm{CO}_{2} \mathrm{CW}, \mathrm{P}=2 \mathrm{~W}, \lambda=10.6 \mu \mathrm{m}$,

- Nd-Yag, $E_{a v}=409 \mathrm{~mJ}, \mathrm{f}=20 \mathrm{~Hz}, \mathrm{t}=5.9 \mathrm{~ns}, \lambda=1.64 \mu \mathrm{m}$,

- $\mathrm{H}_{2}, \mathrm{P}=1.5 \mathrm{~W}, \mathrm{f}=20 \mathrm{kHz}, \mathrm{t}=50 \mathrm{~ns}, \lambda=510 \mathrm{~nm}+578 \mathrm{~nm}$.

\section{Results}

Experiment $1 \mathrm{a}$ - penetration of e-m field $(40 \mathrm{~W})$ into the uniform phantom $(7.9 \mathrm{~g} / \mathrm{l} \mathrm{NaCl})$. The phantom was cut into parts as it is shown on fig.2, to allow fast removal of cutted pieces to observe the temperature distribution inside the phantom. The results are shown on fig. $4 a, b$ for irradiation lasting $1.5 \mathrm{~min}$.

Experiment $1 \mathrm{~b}$ - penetration of thermal wave generated by a set of halogen lamps $20 \times 50 \mathrm{~W}$, distance from the phantom $\mathrm{d}=10 \mathrm{~cm}$, excitation time $30 \mathrm{~s}$, fig. $4 \mathrm{c}$.
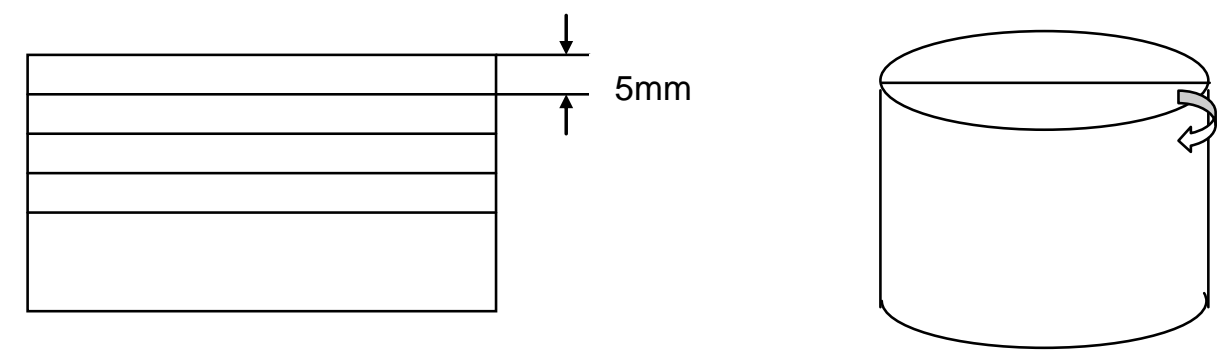

Figure 2. Geometry of phantoms used in the experiment 1

Experiment 2 - penetration of e-m field $(40 \mathrm{~W})$ into the phantom with 6 cells of different concentration of $\mathrm{NaCl}$ (see for details on fig 3). The results are shown on fig. 5a,b for irradiation lasting 3min.

Phantom parameters - experiment 2

\begin{tabular}{|c|c|c|}
\hline $\begin{array}{l}\text { Field } \\
\text { number }\end{array}$ & $\begin{array}{c}\text { Concentration } \\
\text { of } \mathrm{NaCl}[\mathrm{g} / \mathrm{l}]\end{array}$ & $\begin{array}{c}\text { Conductivity } \\
{[\mathrm{S} / \mathrm{m}] \text { at } 20^{\circ} \mathrm{C}}\end{array}$ \\
\hline 0 & 0 & 1.4349 \\
\hline 1 & 7.9 & 2.7657 \\
\hline 2 & 25 & 5.3629 \\
\hline 3 & 44 & 7.8942 \\
\hline 4 & 64 & 10.2609 \\
\hline 5 & 90 & 12.9924 \\
\hline
\end{tabular}

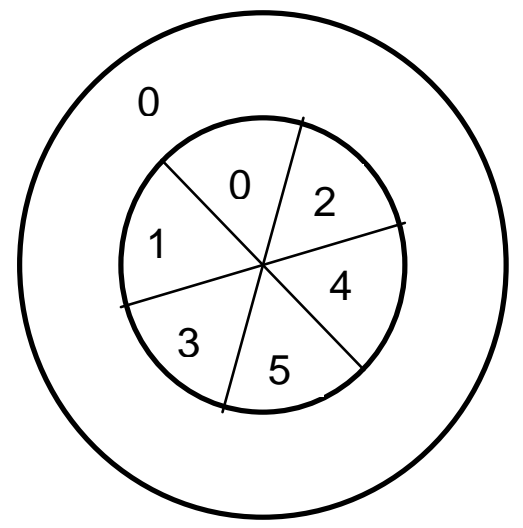

Figure 3.The structure of a 6 -field phantom 
Experiment 3 - penetration of e-m field (40W) into the phantom with 6 cells of different concentrations of dry gel. The results are shown on fig. $6 a, b$ for irradiation lasting 1.5 $\min$.

Experiment 4 - the gelatine phantom (150 $\mathrm{g} / \mathrm{l}, 7.9 \mathrm{~g} / \mathrm{l} \mathrm{NaCl}$ ) with different distortion inside: copper powder, aluminium powder and filing of brass placed on two depths: $3 \mathrm{~mm}$ and $5 \mathrm{~mm}$ under the surface.

$4 a$ - microwave investigation: irradiation time $\mathrm{t}=3 \min , \mathrm{P}=40 \mathrm{~W}$;

$4 \mathrm{~b}$ - halogen lamps (20x50W), excitation

TABLE 1. Phantom parameters - experiment 3

\begin{tabular}{|c|c|c|}
\hline $\begin{array}{l}\text { Field } \\
\text { number }\end{array}$ & $\begin{array}{l}\text { Concentration } \\
\text { of dry gel [g/l] }\end{array}$ & $\begin{array}{c}\text { Concentration } \\
\text { of } \mathrm{NaCl}[\mathrm{g} / \mathrm{l}]\end{array}$ \\
\hline 0 & 100 & 7.9 \\
\hline 1 & 50 & 7.9 \\
\hline 2 & 120 & 7.9 \\
\hline 3 & 30 & 7.9 \\
\hline 4 & 150 & 7.9 \\
\hline 5 & 200 & 7.9 \\
\hline
\end{tabular}
time $\mathrm{t}=10 \mathrm{~s}$. The results are shown on fig. 7 .

Several measurements using semiconductor and laser sources are not shown.

Experiments 2 and 3 were done using the set of halogen lamps, too. The obtained results are similar to those done using the microwave radiation in the experiment 3 . In the experiment 2 thermal properties of gel segments were very similar so the effect of electrical segmentation was evident only in e-m excitation.

The electrical and thermal properties of phantoms are collected in tab. 2.

TABLE 2. Electrical [4] and thermal (done by M. Hryciuk) properties of tissues

\begin{tabular}{|c|c|c|c|c|}
\hline \multirow[t]{2}{*}{ Tissue } & \multirow{2}{*}{$\begin{array}{c}\text { Conductivity [S/m] } \\
\text { at } 2.45 \mathrm{GHz}\end{array}$} & \multirow{2}{*}{$\begin{array}{l}\text { Material } \\
\text { (in vitro) }\end{array}$} & \multicolumn{2}{|c|}{ Thermal parameters } \\
\hline & & & $\mathrm{k}\left[\mathrm{W} / \mathrm{m}^{\star} \mathrm{K}\right]$ & $\rho c_{p}\left[\mathrm{Ws} / \mathrm{cm}^{3} \mathrm{~K}\right]$ \\
\hline Skin & 1.9 & Pig's liver & 0.414 & 22112.71 \\
\hline Muscle & 1.84 & Pig's muscle & 0.4171 & 23013.50 \\
\hline Liver & $2-2.04$ & Pig's fat & 0,1933 & 38686.07 \\
\hline Blood & $3.1-3.5$ & Gelatine $150 \mathrm{~g} / \mathrm{l}$ & 0.4914 & 24802.93 \\
\hline Gelatine & See figure 3 & Gelatine $200 \mathrm{~g} / \mathrm{l}$ & 0.4599 & 25843.36 \\
\hline & & Gelatine $90 \mathrm{~g} / \mathrm{l}$ & 0.4946 & 25057.41 \\
\hline
\end{tabular}

The measurement procedure is performed in following steps:

1. Mechanical matching of the microwave source to a phantom and then generation of microwave heating power (with different levels of power excitation). The equivalent step is relating to optical excitations, too.

2. Thermographic registration of surface temperature distribution and its time changes after removal of the heating source.

3. Calculation of interesting parameters and visualisation of results.

\section{Discussion}

Phantoms used in experiments have thermal and electrical properties similar to biological tissues. This is very important when one wants to use the tested equipment for in vitro and in vivo measurements as the results of phantom measurements may be used for preliminary study of real measurement conditions.

The results shown on fig. 4 enable comparison of e-m and optical excitation in terms of heat penetration. Unfortunately the e-m distribution is not very uniform what may be not properly interpreted on thermograms in clinical use. Also the direct thermal contact of the e$\mathrm{m}$ applicator with the surface of a tested object (here phantom) is responsible for some additional heat flows difficult for interpretation in clinical use. Important advantage of the e-m source is the possibility of selected interaction with tissues of different electrical properties as it is shown on fig. 5 for the gel of different electrical conductivity.

The e-m wave should be penetrating to deeper layers than optical excitation but the difference is not as big as we expected basing on the data given in table $3[5]$ - see fig. $4 a$ and $\mathrm{c}$. 
TABLE 3. Wavelengths and penetration depths for typical tissue with low and high water content at $2.45 \mathrm{GHz}[5]$

\begin{tabular}{|l|c|c|c|c|}
\hline \multicolumn{1}{|c|}{ Water content } & $\begin{array}{c}\lambda \text { in air } \\
{[\mathrm{cm}]}\end{array}$ & $\lambda$ in tissue $[\mathrm{cm}]$ & Conductivity $\sigma[\mathrm{s} / \mathrm{m}]$ & $\begin{array}{c}\text { Penetration } \\
\text { depth }[\mathrm{cm}]\end{array}$ \\
\hline High (muscle, skin) & 12.2 & 1.76 & 2.21 & 1.70 \\
\hline Low (fat, bones) & 12.2 & 5.21 & $0.96-2.13$ & 11.2 \\
\hline
\end{tabular}

Determination of tissues different due to mass density or thermal capacitance or thermal conductivity is more convenient using optical sources for excitation as it is evidenced on fig. 6 and 7. Additional argument for the use of optical excitation is it's totally non-contact operation. This is of the highest importance for medical practice in terms of sterilisation of instrumentation and safety of a patient.

\section{Conclusions}

The performed studies proved that both e-m and optical excitations could be used in active thermography experiments. Unfortunately the use of a microwave source is practically not easy. The main problem is in proper matching of such a source with a tested object. The distribution of e-m field is strongly dependent on electrical properties of a tested object. Therefore a lot of work would be necessary for optimal construction of e-m applicators useful in clinical practice. Also the use of an instrument requiring direct contact to a tested surface seems to be not as handy and safe as in the case of non-contact optical sources.

The main advantage of using the microwave source is the depth of heat penetration up to $2-3 \mathrm{~cm}$ under the surface of the phantom, when for optical excitation the evaluated depth is about $10 \mathrm{~mm}$ and is mainly connected with heat conduction in the material. This is not a general statement as the heat penetration strongly depends on the frequency of irradiation. Additional advantage of e-m sources is the selectivity of interaction with tissues of different electrical properties, what may be important in cancer studies.

The results of the use of semiconductor infra-red excitation sets and several lasers, not shown due to the lack of space, are also very interesting from the point of view of clinical use. Other not possible in phantom studies complications are connected with blood flow. The work is still under progress but preliminary results shown for burn studies (this issue) are extremely interesting in terms of practical importance of active thermography in medical practice.

\section{References}

[1] Pennes H. H., Analysis of tissue and arterial blood temperatures in the resting human forearm, J. Appl. Physiol, no 93, 1948,

[2] Hryciuk M., Pomiary termicznych właściwości tkanek biologicznych (in Polish), Proc. XI Conf. Biocybernetyka i Inzynieria Biomedyczna, 397 - 402, Warszawa, 1999,

[3] Okoniewska E., Okoniewski M., Dębicki P., Relative $\sigma|E|^{2}$ patterns in multilayered biological tissue exposed to a cylindrical waveguide applicator, IEE Conf. Publ 301, Sixth ICAP 89, Coventry, Great Britain, 1989,

[4] Dębicki P., Microwave hyperthermia for the prostate treatment - Hipertermia mikrofalowa w leczeniu gruczolu krokowego (in Polish), ISBN 83-88007-29-7, Politechnika Gdanska, monografie 11, Gdansk 1999,

[5] Duck F. A., Physical Properties of Tissue - Comprehensive Reference Book, Academic Press, 1990. 


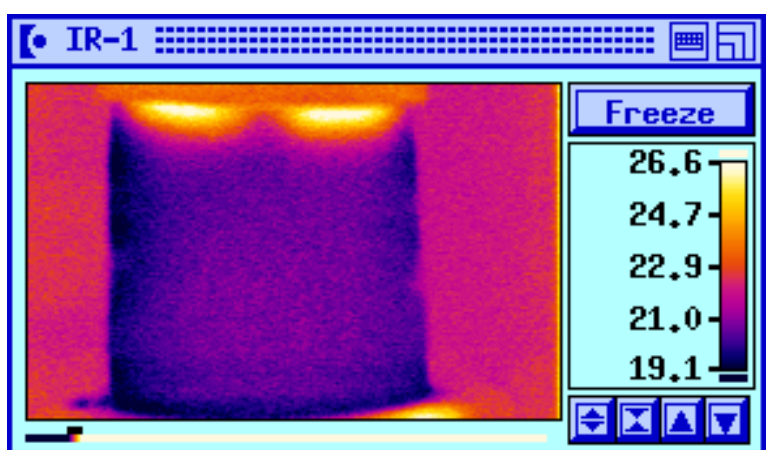

Figure 4a. Experiment 1a using microwave excitation - the homogeneous phantom of the height $12 \mathrm{~cm}$ - the thermogram
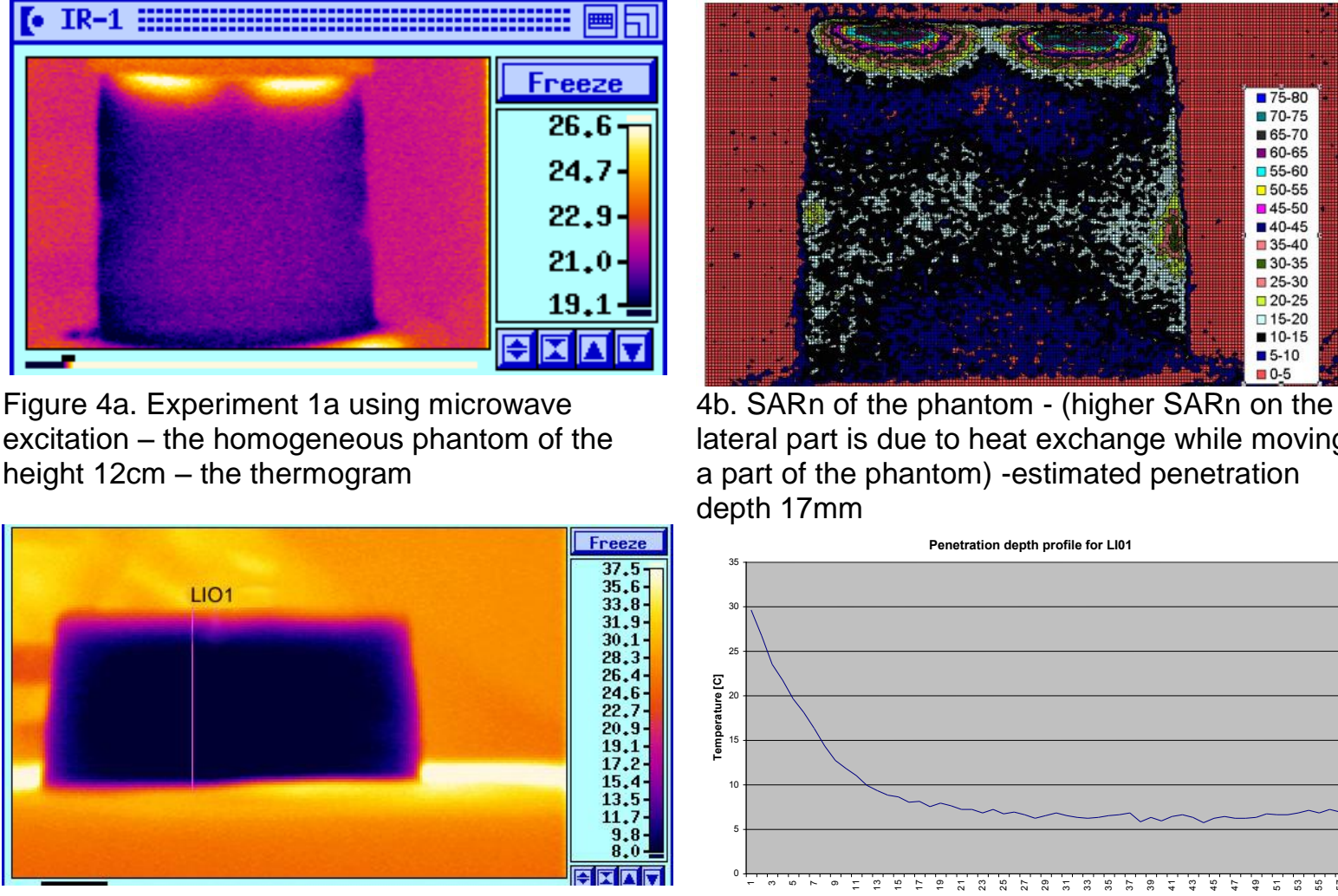

4b. SARn of the phantom - (higher SARn on the lateral part is due to heat exchange while moving a part of the phantom) -estimated penetration depth $17 \mathrm{~mm}$

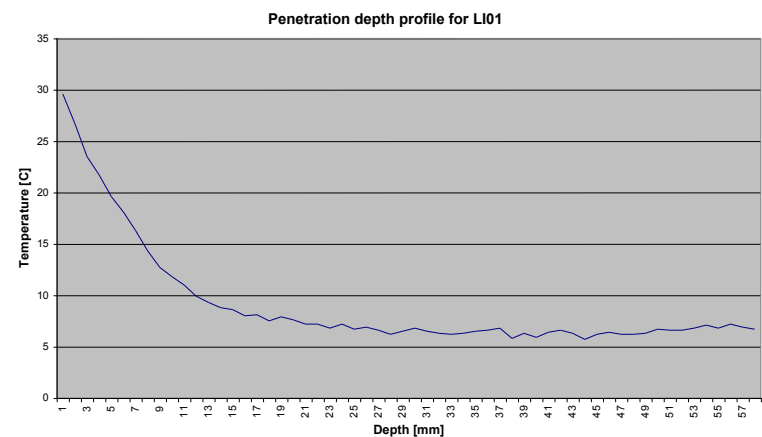

4c. Thermogram and penetration profile for the line LIO1 of the phantom - experiment $1 \mathrm{~b}$ using optical excitation - estimated penetration depth $10 \mathrm{~mm}$

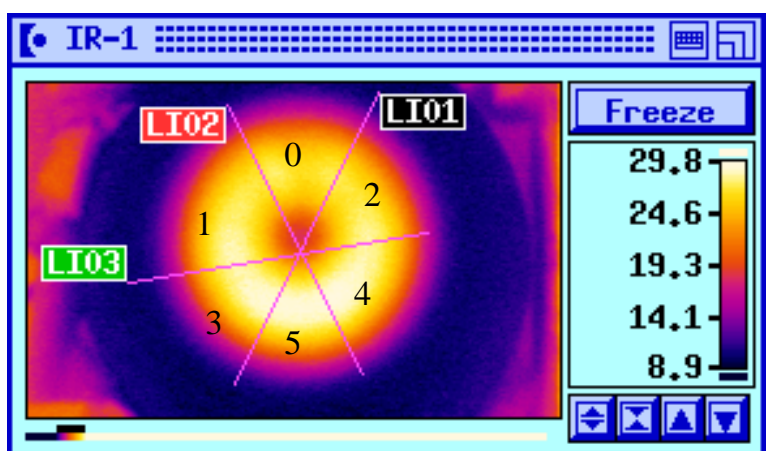

Figure 5a. Experiment 2 - microwave excitation thermogram of the phantom with different concentration of $\mathrm{NaCl}-$ see fig. 3

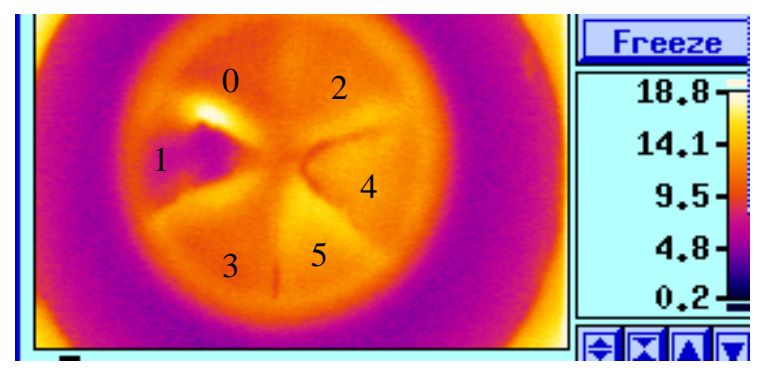

Figure 6a. Experiment 3 - microwave excitation thermogram of the phantom with different concentration of gelatine- see tab. 1 (lower temperature in "1" is due to lower level of gelatine in this cell)

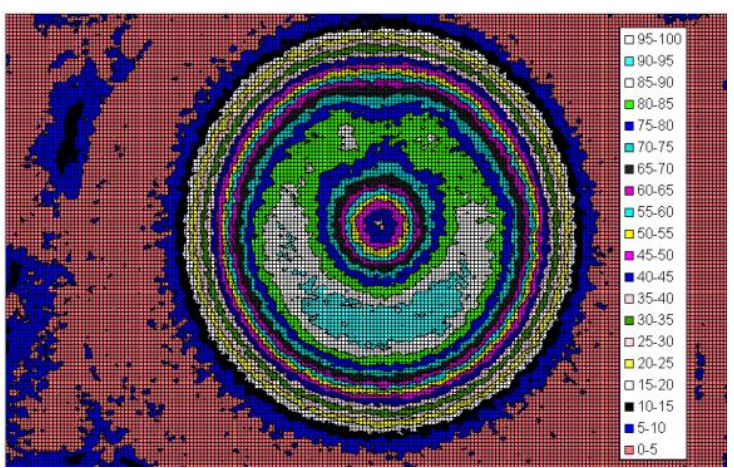

5b. SARn of the phantom

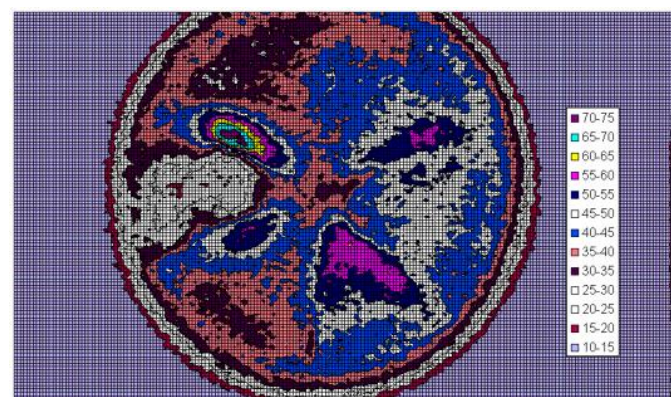

6b. Calculated SARn of the phantom 

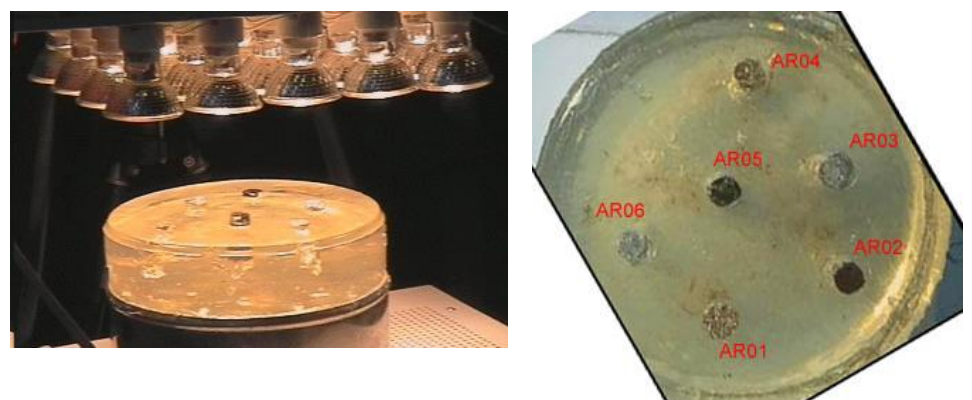

Figure $7 \mathrm{a}$. Photo of the experiment 4 set-up and the phantom with different defects inside

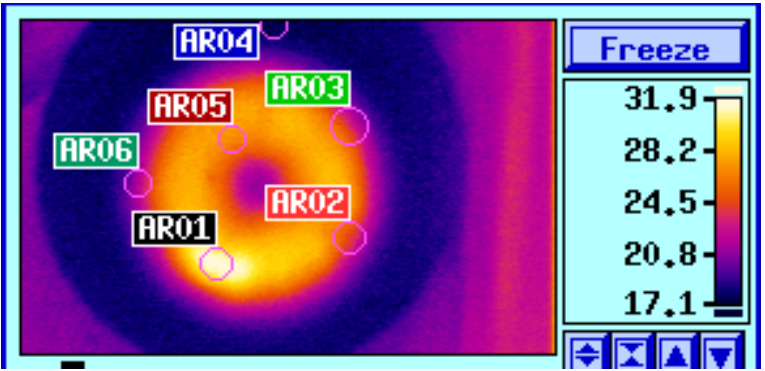

different distortions indicated by circles:

ARO1 - 3mm deep - brass with gel,

ARO2 - 3mm deep - copper with gel,

ARO3 - aluminium 2,

ARO4 - 5mm deep - brass with gel,

ARO5 - 5mm deep - copper with gel,

ARO6 - just under the surface - aluminium 1

Figure $7 \mathrm{~b}$. Experiment $4 \mathrm{a}-$ microwave excitation

3 minutes - thermogram of the phantom after irradiation
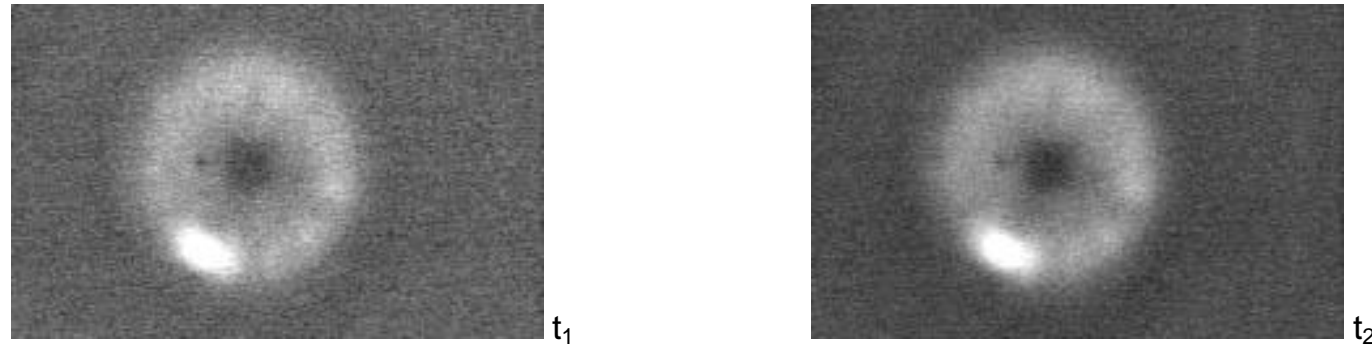

7c. Calculated maximum thermal contrast images - cooling phase for time: $t_{1}=60 \mathrm{~s}, \mathrm{t}_{2}=95 \mathrm{~s}$ for

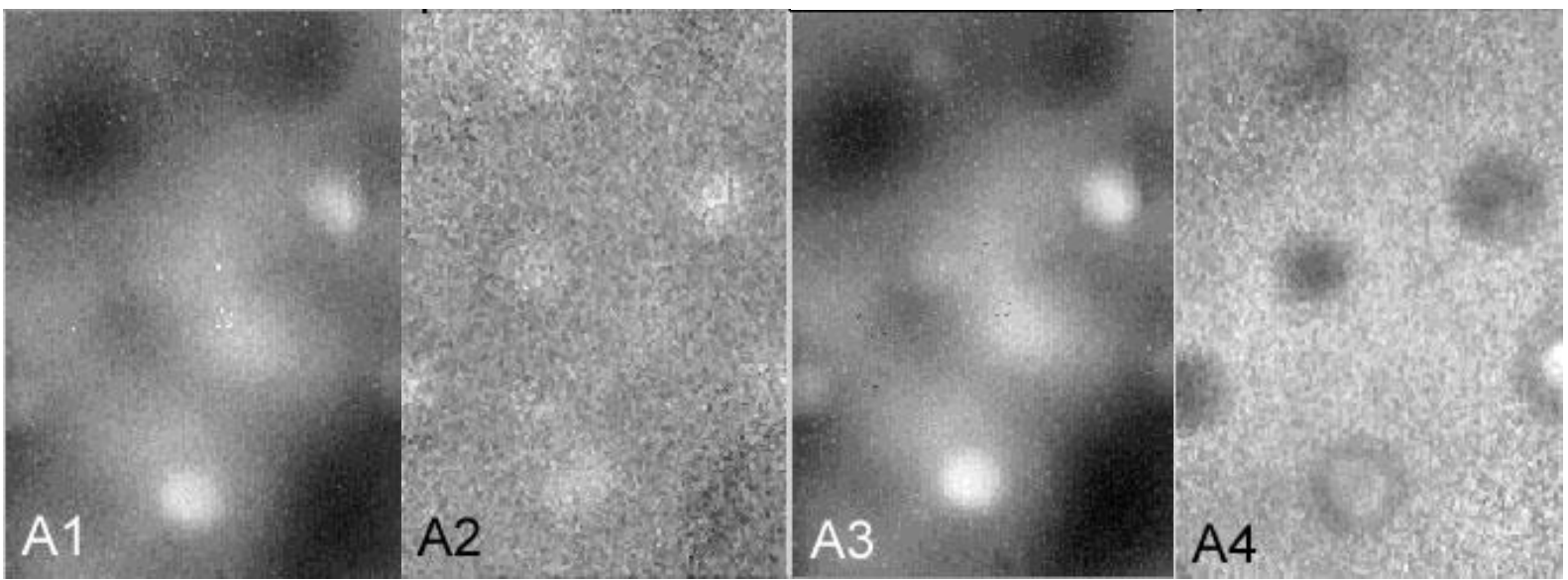

7d. Experiment $4 \mathrm{~b}$ - optical excitation 10 seconds, measurements while cooling; - visualisation of the two exponential model parameters: $\Phi(t)=A 1^{\star} \exp \left(-A 2^{\star} t\right)+A 3^{\star} \exp \left(-A 4^{\star} t\right)$ 